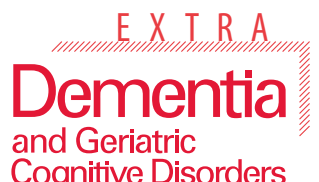

Cognitive Disorders

\begin{tabular}{l|l}
\hline DOI: 10.1159/000323417 & O 2011 S. Karger AG, Basel \\
Published online: Jnuary 14,2011 & www.karger.com/dee
\end{tabular}

Published online: January 14, 2011

www.karger.com/dee

This is an Open Access article licensed under the terms of the Creative Commons AttributionNonCommercial-NoDerivs 3.0 License (www.karger.com/OA-license), applicable to the online version of the article only. Distribution for non-commercial purposes only.

\title{
Screening for New Biomarkers for Subcortical Vascular Dementia and Alzheimer's Disease
}

\author{
Annika Öhrfelt ${ }^{\mathrm{a}}$ Ulf Andreasson $^{\mathrm{a}}$ Adam Simon $^{\mathrm{b}, \mathrm{c}}$ \\ Henrik Zetterberg $^{a}$ Åke Edman ${ }^{a}$ William Potter $^{b}$ Daniel Holder ${ }^{b}$ \\ Viswanath Devanarayan ${ }^{b, d}$ Jeffrey Seeburger ${ }^{b}$ A. David Smith ${ }^{e}$ \\ Kaj Blennow ${ }^{\text {a }}$ Anders Wallin ${ }^{a}$ \\ a Department of Psychiatry and Neurochemistry, Institute of Neuroscience and Physiology, \\ Sahlgrenska Academy, University of Gothenburg, Mölndal, Sweden; ${ }^{b}$ Department of \\ Alzheimer's Research, Merck Research Laboratories, West Point, Pa., 'Neuronostics, LLC,

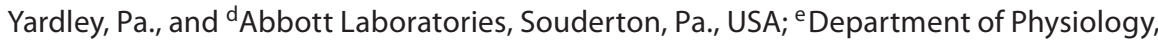 \\ Anatomy and Genetics, University of Oxford, Oxford, UK
}

\section{Key Words}

Alzheimer's disease $\cdot$ Biomarkers $\cdot$ Cerebrospinal fluid $\cdot$ Mild cognitive impairment $\cdot$ Vascular dementia

\begin{abstract}
Background: Novel biomarkers are important for identifying as well as differentiating subcortical vascular dementia (SVD) and Alzheimer's disease (AD) at an early stage in the disease process. Methods: In two independent cohorts, a multiplex immunoassay was utilized to analyze 90 proteins in cerebrospinal fluid (CSF) samples from dementia patients and patients at risk of developing dementia (mild cognitive impairment). Results: The levels of several CSF proteins were increased in SVD and its incipient state, and in moderate-to-severe AD compared with the control group. In contrast, some CSF proteins were altered in AD, but not in SVD. The levels of heart-type fatty acid binding protein (H-FABP) were consistently increased in all groups with dementia but only in some of their incipient states. Conclusions: In summary, these results support the notion that SVD and AD are driven by different pathophysiological mechanisms reflected in the CSF protein profile and that H-FABP in CSF is a general marker of neurodegeneration.

Copyright $\odot 2011$ S. Karger AG, Basel




\section{Introduction}

Age is the major risk factor for developing different types of dementia, thus disease prevalence increases significantly with increasing life expectancy [1]. Today, only symptomatic treatment is available for patients with Alzheimer's disease (AD), the most common type of dementia. However, promising medical treatment strategies carry hope for disease-modifying therapies, and when these become available, it will be of great importance to have biomarkers that can aid in the diagnosis and monitoring of treatment efficacy. For correct treatment and to provide clinical drug trials including subjects at risk of developing a specific disease, it is also crucial to be able to detect and discriminate between different dementia forms preferably at a preclinical stage $[2,3]$. In addition, as there are treatment strategies for vascular cognitive impairment, the second most common type of dementia, it is of great importance to identify vascular causes of cognitive impairment at an early stage [4]. Biochemical studies of subjects with mild cognitive impairment (MCI), a transitional state which might vary from normal aging to dementia [5], are therefore important. Previous studies have shown that some biomarkers are altered before symptomatic disease presents clinically $[3,6]$, but the identification of new markers is still warranted.

The metabolism in the brain is believed to be reflected in the composition of the cerebrospinal fluid (CSF), which makes CSF an ideal source for biomarkers related to dementia. In the present study, CSF levels of 90 different proteins were investigated for their potential as biomarkers differentiating healthy controls from three different types of dementia, i.e. subcortical vascular dementia (SVD), AD, and mixed types of dementias (MD), in both their incipient (before dementia) and overt (dementia) states. SVD is predominantly characterized by small vessel disease and brain oxygen deficiency, leading to white matter lesions, lacunar infarcts, and incomplete ischemic injury [7]. AD is a progressive neurodegenerative disorder that is neuropathologically characterized by abnormal accumulation of intraneuronal neurofibrillary tangles and extracellular amyloid plaques throughout the cortical and limbic brain regions [8]. The etiologies of SVD and AD may be distinct but they also co-exist as MD [9].

Here, we tested the diagnostic and discriminative power of a recently developed multiplex immunoassay of 90 CSF proteins in two independent cohorts: patients with dementia and those at risk of developing dementia. The results indicate that the profiles of the measured CSF proteins differ at a group level depending on the established diagnosis and severity of dementia. These findings are promising but need to be confirmed in independent studies.

\section{Materials and Methods}

\section{CSF from Gothenburg Subjects}

At baseline, the study group consisted of 52 controls, 8 subjects with SVD, 24 subjects with probable AD, 14 subjects with MD, and 152 subjects with MCI. During either an observational time of $2(n=77)$ or 4 years $(n=75)$, depending on the time of enrollment into the study, 7 of the MCI subjects progressed to SVD (MCI-SVD), 15 progressed to AD (MCI-AD), 10 progressed to MD (MCI-MD), 8 were considered to recover (MCI-norm), while 112 had stable disease (stable MCI; table 1).

Lumbar puncture was performed in the morning under standard conditions. Twelve milliliters of CSF were collected in polypropylene tubes and gently mixed to avoid gradient effects. CSF samples with $>500$ erythrocytes/ $\mu$ l were excluded, which is important to avoid contamination with blood proteins. All samples were centrifuged to remove cells and debris, and stored in aliquots at $-80^{\circ} \mathrm{C}$ pending biochemical analysis. 
Table 1. Patients' characteristics and demographics for the Gothenburg MCI study

\begin{tabular}{lcllllll}
\hline Groups & $\begin{array}{l}\text { Subjects, } \mathrm{n} \\
(\mathrm{F} / \mathrm{M})\end{array}$ & $\begin{array}{l}\text { Age } \\
\text { years }\end{array}$ & p value & $\begin{array}{l}\text { MMSE at } \\
\text { baseline }\end{array}$ & p value & $\begin{array}{l}\text { MMSE at } \\
\text { follow-up }\end{array}$ & p value \\
\hline Control & $52(31 / 21)$ & $67(63-73)$ & & $30(29-30)$ & & $29(29-30)$ & \\
Mild AD & $24(18 / 6)$ & $65(58-69)$ & 0.658 & $26(22-27)$ & $<0.0001$ & $21(14-24)$ & $<0.0001$ \\
MD & $14(7 / 7)$ & $72(65-76)$ & 0.023 & $23(21-24)$ & $<0.0001$ & $17(11-22)$ & $<0.0001$ \\
SVD & $8(2 / 6)$ & $72(67-75)$ & 0.064 & $26(25-26)$ & $<0.0001$ & $23(21-29)$ & 0.002 \\
Stable MCI & $112(55 / 57)$ & $62(57-68)$ & 0.020 & $29(28-30)$ & 0.005 & $29(28-30)$ & 0.608 \\
MCI-AD & $15(10 / 5)$ & $66(61-71)$ & 0.679 & $28(27-28)$ & $<0.0001$ & $25(23-26)$ & $<0.0001$ \\
MCI-MD & $10(8 / 2)$ & $69(60-74)$ & 0.521 & $29(25-29)$ & 0.002 & $21(20-25)$ & $<0.0001$ \\
MCI-SVD & $7(3 / 4)$ & $68(67-74)$ & 0.069 & $28(27-29)$ & 0.006 & $26(25-28)$ & 0.006 \\
MCI-norm & $8(4 / 4)$ & $60(58-62)$ & 0.142 & $29(28-30)$ & 0.075 & $30(30-30)$ & 0.095 \\
\hline
\end{tabular}

Medians with interquartile ranges (25th to 75 th percentiles in parentheses) are shown. The MannWhitney test was used to investigate group differences, and each patient subgroup was compared with the control group. Follow-up lasted 2-4 years.

This study is a part of the Gothenburg MCI study for which the diagnostic procedure has been described in detail previously [10]. The procedure for establishing an MCI diagnosis was congruent with the recommendations laid down by the International Working Group on Mild Cognitive Impairment [11] and was in agreement with the MCI criteria defined by Petersen [5]. The diagnosis of dementia was based on the DSM-III-R criteria [12] together with the criteria of NINCDS-ADRDA [13] and ICD-10 [14] with regard to AD, the criteria of Erkinjuntti et al. [15] with regard to SVD, and ICD-10 with regard to MD (AD with cerebrovascular lesions).

Controls were not included if they had subjective or objective signs of a cognitive disorder assessed according to the procedure described above. To be part of this substudy, controls should have CSF/serum albumin ratios [CSF-albumin ( $\mathrm{mg} / \mathrm{l}$ ) divided by serum albumin $(\mathrm{g} / \mathrm{l})]<10.2$, thus reflecting an intact blood-brain barrier function.

The cognitive status was examined using the Mini-Mental State Examination (MMSE). The Ethics Committee at the University of Gothenburg approved the study. All patients or their relatives gave informed consent for participation in the study, which was conducted in accordance with the provisions of the Declaration of Helsinki.

\section{CSF from the Oxford Project to Investigate Memory and Aging}

At baseline, the Oxford Project to Investigate Memory and Aging (OPTIMA) study group consisted of 48 healthy controls, 63 patients with AD (56 definitive and 7 probable), 9 subjects with MCI who progressed to $\mathrm{AD}$, and 7 controls who progressed to MCI (table 2).

Lumbar puncture was performed in the morning, as described previously [16]. Ten to 15 $\mathrm{ml}$ of CSF were collected in polystyrene tubes. CSF samples with visible red color were excluded. All samples were centrifuged to remove cells and debris, and any samples disclosing red cells in the sediment were discarded. Aliquots of the supernatant were transferred to polypropylene tubes for storage at $-80^{\circ} \mathrm{C}$.

This study is a part of the OPTIMA project, for which the clinical and histopathological procedures for AD diagnosis have been described previously [17]. All $63 \mathrm{AD}$ patients were diagnosed histopathologically as definite/probable AD at autopsy. MCI diagnosis was established using the criteria outlined by Petersen [5]. 
Table 2. Patients' characteristics and demographics for the OPTIMA study

\begin{tabular}{lcllllll}
\hline Groups & $\begin{array}{l}\text { Subjects, n } \\
(\mathrm{F} / \mathrm{M})\end{array}$ & $\begin{array}{l}\text { Age } \\
\text { years }\end{array}$ & $\begin{array}{l}\mathrm{p} \\
\text { value }\end{array}$ & $\begin{array}{l}\text { MMSE } \\
\text { baseline }\end{array}$ & $\begin{array}{l}\mathrm{p} \\
\text { value }\end{array}$ & $\begin{array}{l}\text { CAMCOG } \\
\text { baseline }\end{array}$ & $\begin{array}{l}\mathrm{p} \\
\text { value }\end{array}$ \\
\hline Control & $48(22 / 26)$ & $69(64-78)$ & & $29(29-30)$ & & $101(98-102)$ & \\
Moderate-severe AD & $63(40 / 23)$ & $76(67-81)$ & 0.031 & $12(7-16)$ & $<0.0001$ & $42(20-60)$ & $<0.0001$ \\
MCI-AD & $9(5 / 4)$ & $72(62-74)$ & 0.553 & $25(23-26)$ & 0.0003 & $89(84-91)$ & $<0.0001$ \\
Control-MCI & $7(5 / 2)$ & $68(65-69)$ & 0.595 & $30(28-30)$ & 0.860 & $99(96-102)$ & 0.354 \\
\hline
\end{tabular}

Medians with interquartile ranges (25th to 75 th percentiles in parentheses) are shown. The MannWhitney test was used to investigate group differences, and each patient subgroup was compared with the control group.

a The 63 subjects with AD were diagnosed histopathologically with definite or probable AD.

Controls were not included if they had subjective or objective signs of a cognitive disorder, which was assessed using CAMCOG, the cognitive test component of CAMDEX (the Cambridge Examination for Mental Disorders in the Elderly) [18], which allows an MMSE score to be derived. All subjects were assessed by the CAMCOG once a year, but classification of controls is restricted to those who continued to score above the cutoff (80) for cognitive impairment.

Ethical approval for the study was given by the Central Office for Research Ethics Committees of the National Health Service (No. C1656). All patients or their relatives gave informed consent for participation in the study, which was conducted in accordance with the provisions of the Declaration of Helsinki.

For both (the Gothenburg and OPTIMA) studies, CSF taken at baseline was analyzed.

\section{Bead-Based Luminex xMAP Technology}

The concentrations of 90 proteins were determined on blinded samples using a multiplex bead-based service [HumanMAP ${ }^{\circledR}$ version 1.6 kit; Rules-Based Medicine; http://www.rulesbasedmedicine.com/products-services/humanMAP-antigen.asp with a minor modification (also including interleukin-18 but not interferon- $\gamma$ in the Gothenburg study)] at the service providers' facilities in Austin, Tex., USA. This protein panel includes acute phase proteins, growth factors, hormones, tissue markers, vascular factors as well as proteins involved in the angiogenesis, blood hemostasis, immune responses, and lipid metabolism. Many of the proteins have multiple biological functions and can be classified within several of the above groups.

In brief, the XMAP technology is based on flow-cytometric separation of the antibodycoated microspheres that are labeled with a specific mixture of two fluorescent dyes. After binding of a biotinylated reporter antibody, quantification is made by binding of a third fluorochrome coupled to streptavidin. The technique allows multi-analyte testing of one single sample.

To be included in the study, analyte concentrations should be measurable, i.e. exceeding the limit of detection in $>50 \%$ of all the samples for each respective analyte. These criteria were fulfilled by 44 analytes in the Gothenburg study and 45 analytes in the OPTIMA study, and for these analytes values below the limit of detection were conservatively set to this limit.

\section{Statistical Analyses}

All univariate statistical analyses were performed using the Statistical Package of the Social Sciences (SPSS). Because the distributions of most analytes were not normal (Shapiro- 
Wilk test, $\mathrm{p}<0.05)$, non-parametric statistics were used for the analysis. Data are given as medians (interquartile ranges) and percent difference, i.e. $100 \times$ [(the median for each diagnostic group - the median for the control group)/the median for the control group]. The Mann-Whitney test was used to investigate group differences, and each subgroup of patients was compared with the control group. Since for each comparison 44 (Gothenburg) or 45 (OPTIMA) analytes were statistically tested, a false discovery rate was estimated using the method of Benjamini and Hochberg [19]. This rate is the expected proportion of false discoveries amongst the rejected hypotheses and characterized by a Q value, the largest false discovery rate for which an analyte would be positive.

Correlations were calculated using the Spearman two-tailed correlation test. Since multiple correlations were performed, the significance level threshold was more stringently set to $\mathrm{p}<0.01$.

Large data sets are inherently hard to overview, and to better extract information from the immunochemical results a multivariate discriminant analysis (DA) was performed using the orthogonal projections to latent structures (OPLS) algorithm [20, 21] implemented in the software SIMCA P+ (version 12; Umetrics, Umeå, Sweden). This method considers all data at the same time in one analysis and constructs a model that maximizes the separation between different predefined groups. Prior to analysis, each patient group was randomly subdivided into training (80\%) and prediction subsets (20\%), of which only the training sets were used for model construction. For each OPLS-DA analysis, a first model was constructed using data for all the measured proteins that passed the inclusion criteria (see above). Then the final number of analytes used in the models was determined by first deleting all but the five analytes that contributed most to the separation, based on the variable importance in the projection. Further stepwise reduction was performed until a maximum of the goodness of prediction value $\left(\mathrm{Q}^{2}\right)$, resulting from cross-validation [22], was reached. Stability of the final models was tested by external validation in which the similarity between data from the prediction and training sets were judged using the Mann-Whitney test, with $\mathrm{p}<0.05$ indicating a difference between the training and predictions sets.

The relationship between sensitivity and specificity for the different groups of patients versus the controls was described using receiver-operating characteristic (ROC) analysis. The optimal cutoff value from the ROC curve was chosen as the point at which the Youden [23] index is maximal. ROC statistics were calculated based on the training and prediction data sets combined.

\section{Results}

Even though neither age nor MMSE differed significantly between the control groups in the Gothenburg and OPTIMA studies (tables 1,2), there were large differences in many of the measured protein levels between the groups. Also, both age and MMSE differed significantly ( $p<0.0001)$ between the AD subjects from the two centers. For these reasons, statistical group comparisons were only made on subjects from the same center.

Univariate Statistical Analysis

Compared with controls, MD and SVD patients had significantly increased levels of $\alpha_{1^{-}}$ antitrypsin (AAT; 64 and 86\%, respectively), apolipoprotein $\mathrm{H}(\mathrm{ApoH} ; 40$ and 61\%, respectively), plasminogen activator inhibitor-1 (PAI-1; 33 and 47\%, respectively), and tissue inhibitor of metalloproteinase-1 (TIMP-1; 36 and 34\%, respectively). For all of these four proteins, the levels were also significantly increased in patients with MCI who progressed to MD or SVD (fig. 1a-d, online suppl. table 1, www.karger.com/doi/10.1159/000323417). In addi- 


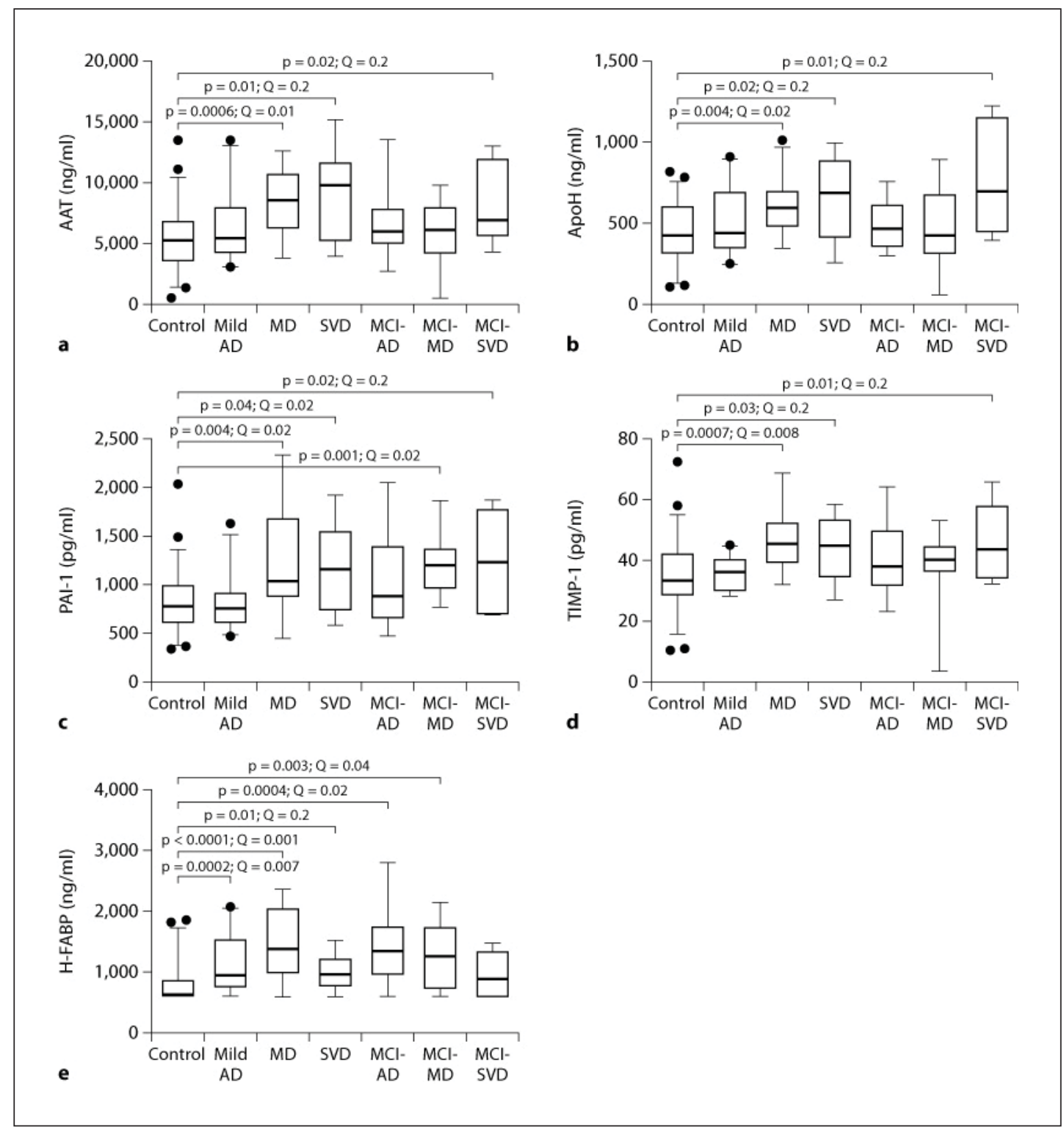

Fig. 1. Box plots of CSF proteins that differed most between controls and different stages of MD and SVD. Within the Gothenburg study, the levels of AAT (a), ApoH (b), PAI-1 (c), TIMP-1 (d), and H-FABP (e) from control individuals $(\mathrm{n}=52)$ and patients with $\operatorname{AD}(\mathrm{n}=24), \operatorname{MD}(\mathrm{n}=14), \operatorname{SVD}(\mathrm{n}=8), \operatorname{MCI}-\operatorname{AD}(\mathrm{n}=15)$, MCI-MD ( $=10)$ and MCI-SVD $(n=7)$. The lower, upper and the middle lines of boxes correspond to 25 th and 75 th percentiles and medians, respectively. The whiskers at the top and bottom extend from the 95th and 5th percentile, respectively.

Fig. 2. Multivariate analysis using OPLS-DA. For the Gothenburg study, controls $(\mathrm{n}=50)$ were compared to $M D$ and MD+SVD ( $=22 ; \mathbf{a}), \operatorname{MCI}-(M D+S V D)(n=17 ; \mathbf{b})$, mild AD ( $=24 ; \mathbf{c})$, and MCI-AD ( $\mathrm{n}=15$; d). For OPTIMA, controls $(\mathrm{n}=48)$ were compared to moderate-severe (mod-sev) AD $(\mathrm{n}=63 ; \mathbf{e})$. P and T denote prediction and training sets, respectively. The dotted lines represent the optimal cutoff-based ROC analysis (see table 3). Corresponding variable importance in projection (VIP) plots (f-j) illustrate the relative contributions of the analytes to the separation between the groups. $\mathrm{AFP}=\alpha$-fetoprotein; $\mathrm{CRP}=$ C-reactive protein. 

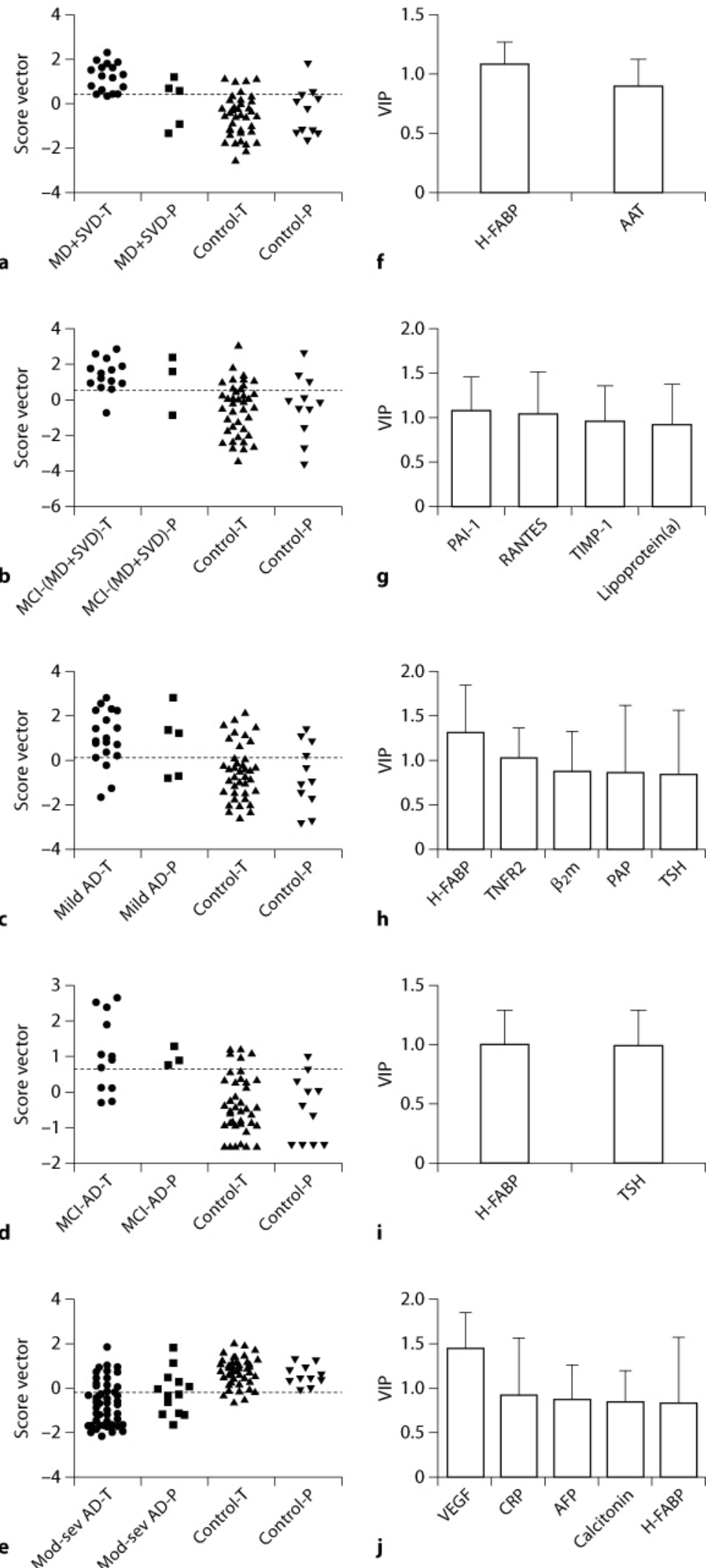
Table 3. Group comparisons based on results from the multivariate discriminant analysis

\begin{tabular}{lllll}
\hline & $\begin{array}{l}\text { Controls/ } \\
\text { patients }\end{array}$ & Sensitivity & Specificity & AUC \\
\hline Control and MD+SVD $^{\mathrm{a}}$ & $52 / 22$ & $86(65-97)$ & $86(73-94)$ & $0.88(0.79-0.97)$ \\
Control and MCI-(MD+SVD) $^{\mathrm{a}}$ & $52 / 17$ & $88(64-99)$ & $74(60-85)$ & $0.83(0.72-0.94)$ \\
Control and mild AD & $52 / 24$ & $79(58-93)$ & $72(58-84)$ & $0.79(0.68-0.90)$ \\
Control and MCI-AD & $52 / 15$ & $73(45-92)$ & $88(76-95)$ & $0.86(0.77-0.96)$ \\
Control and moderate-severe AD & $48 / 63$ & $68(55-79)$ & $95(85-99)$ & $0.86(0.80-0.93)$ \\
\hline
\end{tabular}

ROC curve analysis with the area under the curve (AUC) calculated using data from both training and prediction sets. Analysis is based on the corresponding models in figure 2; $95 \%$ confidence intervals are given in parentheses.

${ }^{a}$ Controls $(n=50)$ and patients from the Gothenburg study: MD+SVD ( $\left.=22\right)$, MCI- $(M D+S V D)$ $(\mathrm{n}=17), \operatorname{AD}(\mathrm{n}=24)$, and MCI-AD $(\mathrm{n}=15)$.

b Controls $(n=48)$ and AD subjects $(n=63)$ from the OPTIMA study.

tion, the levels of AAT, ApoH, and TIMP-1 were significantly increased in patients with moderate-severe $\operatorname{AD}(36,29$ and 5\%, respectively; OPTIMA), but not in patients with mild $\mathrm{AD}$ within the Gothenburg study compared with the control group (online suppl. table 1).

The levels of heart-type fatty acid binding protein (H-FABP) were significantly increased in patients with mild $\mathrm{AD}(46 \%)$ moderate-severe $\mathrm{AD}(47 \%), \mathrm{MD}$ (113\%), SVD (49\%), MCIAD (Gothenburg; 108\%) and MCI-MD (94\%) compared with the control group (fig. 1e, online suppl. table 1). Similarly, the levels of lipoprotein(a) were significantly increased in patients with mild AD (31\%), MD (59\%), SVD (59\%), MCI-AD (OPTIMA; 68\%), MCI-MD (46\%), and MCI-SVD (82\%) compared with the control group (online suppl. table 1).

The levels of soluble tumor necrosis factor receptor 2 (TNFR2) were significantly increased in patients with mild AD (15\%) and moderate-severe AD (15\%), MD (41\%) and MCISVD (40\%) compared with the control group (online suppl. table 1).

The levels of thyroid-stimulating hormone (TSH) were significantly altered in patients with mild AD (46\%) and moderate-severe AD (-40\%), MCI-AD (Gothenburg; 81\%) and MCI-SVD (169\%) compared with the control group (online suppl. table 1).

Many proteins were significantly altered in patients with moderate-severe AD compared with the control group, e.g. $\alpha$-fetoprotein (11\%), calcitonin (108\%), C-reactive protein (57\%), ENRAGE (50\%), and vascular endothelial growth factor (VEGF; -19\%), but they were unchanged in mild $A D$. In contrast, $\beta_{2}$-microglobulin $\left(\beta_{2} \mathrm{~m}\right)$ levels were significantly increased in patients with mild $\mathrm{AD}(30 \%)$ compared with the control group, but not in moderate-severe AD (online suppl. table 1).

\section{Multivariate Statistical Analysis}

The different patient groups, MD+SVD, MCI-(MD+SVD), mild AD, MCI-AD (Gothenburg), and moderate-severe $\mathrm{AD}$ were compared to controls using multivariate $\mathrm{DA}$, and the results are shown in figure 2; the corresponding ROC analysis is summarized in table 3 . All dementia subgroups were significantly different $(\mathrm{p}<0.0001)$ from the controls (fig. $2 \mathrm{a}-\mathrm{e})$, although due to different proteins (fig. $2 \mathrm{f}-\mathrm{j}$ ). Almost all of these proteins were lower in the control group than in the dementia groups. The only exceptions were prostatic acid phosphatase (PAP) in mild AD (fig. 2h) and VEGF in moderate-severe AD (fig. 2j), which were both lower compared to controls. 
There was a high sensitivity (86\%) for detecting MD+SVD and also a high specificity (86\%) for discriminating MD+SVD from the control group (fig. 2a; table 3). Both H-FABP and AAT contributed to the separation between the two groups (fig. 2f), which is in agreement with the univariate analyses showing increased levels of these proteins in patients with MD or SVD compared with controls. There was also a high sensitivity (88\%) for detecting MCI-(MD+SVD) and a moderate specificity (74\%) for discriminating MCI-(MD+SVD) from the control group (fig. 2b; table 3). PAI-1, RANTES, TIMP-1, and lipoprotein(a) contributed to the separation between the two groups (fig. $2 \mathrm{~g}$ ).

The combination of 5 proteins, H-FABP, TNFR2, $\beta_{2} \mathrm{~m}$, PAP, and TSH, helped to discriminate mild AD from controls with a sensitivity and specificity of 79 and $72 \%$, respectively (fig. 2c, h; table 3). The corresponding figures for MCI-AD (Gothenburg) were 73 and $88 \%$ (table 3), respectively, with equal contribution of H-FABP and TSH to the separation (fig. 2d, i). These two proteins were already different in the MCI-AD (Gothenburg) group (fig. 1d, i).

For the OPTIMA study, multivariate analysis enabled to distinguish between moderatesevere $\mathrm{AD}$ and controls with sensitivity and specificity estimates of 68 and $95 \%$, respectively. Only H-FABP was among the five analytes that contributed most to the separation between $\mathrm{AD}$ and controls in both the Gothenburg and the OPTIMA studies (fig. 1h, j).

Internal and external validations were performed to assess the stability of the multivariate models and both tests indicate, based on the criteria given in Materials and Methods, that the separation is not due to overfitted models (fig. 2a-e).

There was no general statistically significant correlation between the albumin ratio and the panel of analyte concentrations within any of the diagnostic groups. Only a few patients with MD, SVD, and their incipient states had albumin ratios above the highest reference value (data not shown).

\section{Discussion}

In this study, the concentrations of 90 different proteins were assessed in the CSF from healthy controls and patients with dementia at different stages, and the results suggest that the protein profile differs between disorders and is dynamic in the disease process. For MD and SVD, the CSF levels of AAT, TIMP-1, PAI-1, and ApoH were all increased compared to healthy controls. AAT is an acute phase protein that is involved in inflammatory responses [24] and TIMP-1 is a major regulator of extracellular matrix synthesis/degradation and participates in angiogenesis and inflammatory responses [25]. PAI-1 is a regulator of fibrinolysis [26], and $\mathrm{ApoH}$ also prevents activation of the blood coagulation cascade [27]. Interestingly, the levels of these proteins were altered in a disease-specific manner already at the MCI stage in patients that later had MD or SVD, indicating that changes in the processes are relatively early events in the etiology of these disorders. Both inflammatory [28] and hemostatic factors [29] have previously been suggested to be involved in the etiology of different types of dementia.

In contrast, the levels of AAT, ApoH, and TIMP-1 were significantly increased only in patients with severe $\mathrm{AD}$, but not in the cohorts with incipient or mild $\mathrm{AD}$. However, since there was a large difference in age between the patients with severe AD and the other groups, an age effect on the protein levels cannot be excluded.

A very consistent finding was the increase in H-FABP in all groups, except for MCI-SVD, compared with controls. H-FABP functions in the intracellular lipid metabolism by carrying fatty acids, and elevated CSF levels of this protein have previously been reported in studies on dementia and Creutzfeldt-Jakob disease [30], which suggests that H-FABP in CSF is a general marker for neurodegeneration. 
Other proteins that differed in some groups compared to the controls include TNFR2, which was recently shown to be increased in patients with MCI developing AD and vascular dementia [31], and TSH, a hormone that activates the thyroid gland. Elevated TSH levels in blood samples have previously been associated with dementia [32].

As expected, the multivariate model achieved better separation than the separate analysis of each analyte, as judged from the ROC analysis. The analytes that differed already in the univariate analysis, as discussed above, also presented as important variables for the separation between different groups.

None of the proteins that contributed most to the separation between MD+SVD and controls did so at the MCI stage. This might be due to the heterogeneity caused by combining MD and SVD cases, but also by different contributions of SVD and AD in the MD cases. However, it may also imply that the protein profile in CSF is dynamic depending on the stage of the disease. If so, the profile could be a valuable tool for determining disease progression in MD and SVD. In contrast, for AD both H-FABP and TSH contribute to the discrimination already at the MCI stage, which suggests a timeline where changes in H-FABP and TSH precede alterations in TNFR2, $\beta_{2} \mathrm{~m}$, and PAP in the disease process.

There was no consistent correlation between the albumin ratio and panel analyte concentrations within any of the diagnostic groups, which suggests that the measured CSF protein concentrations are not influenced by leakage across the blood-brain barrier. Only a few patients within the group of $M D+S V D$ and their incipient state had albumin ratios above the highest reference value (data not shown). This is contradictory to previous studies that have shown that blood-brain barrier functions are impaired in dementia with white matter changes [33].

A limitation of the present study is that in the control groups from the Gothenburg and OPTIMA cohorts the measured levels of several proteins analyzed differed significantly, which prohibited combining of the two cohorts. As a consequence, the Gothenburg data did not perform well in the OPTIMA model and vice versa (data not shown). The reason for the difference is presently unknown but pre-analytical factors, e.g. sample handling, may contribute to the variation. The observed center-to-center variation is not unique, and in a recent large multicenter study the need for a standardized protocol for clinical procedures was proposed to eliminate confounding factors that render comparisons of studies from different centers difficult [34].

\section{Conclusions}

The present results suggest that the pathological changes, reflected in the CSF composition, occur several years before clinical symptoms manifest. However, future studies with a longitudinal design are required to establish the potential use of the analytes investigated as biomarkers.

\section{Acknowledgments}

The authors would like to thank Gunnar Brinkmalm for providing macroprograms to Microsoft Office Excel. This work was supported by grants from the Swedish Brain Power, Swedish Research Council (project 2007-14002, 09946), Stiftelsen Gamla Tjänarinnor, Alzheimer's Association (award No. NIRG-08-90356), cNEUPRO, the Royal Swedish Academy of Sciences, the Sahlgrenska University Hospital, the Inga-Britt and Arne Lundberg Research Foundation, the Gothenburg Medical Society, the Åke Wiberg Foundation, the Gun och Bertil Stohnes Stiftelse and the Alzheimer Foundation, Sweden. 


\section{References}

1 Christensen K, Doblhammer G, Rau R, Vaupel JW: Ageing populations: the challenges ahead. Lancet 2009;374:1196-1208.

-2 DeCarli C: Mild cognitive impairment: prevalence, prognosis, aetiology, and treatment. Lancet Neurol 2003;2:15-21.

-3 Hansson O, Zetterberg H, Buchhave P, Londos E, Blennow K, Minthon L: Association between CSF biomarkers and incipient Alzheimer's disease in patients with mild cognitive impairment: a followup study. Lancet Neurol 2006;5:228-234.

-4 Hachinski V, Iadecola C, Petersen RC, Breteler MM, Nyenhuis DL, Black SE, Powers WJ, DeCarli C, Merino JG, Kalaria RN, Vinters HV, Holtzman DM, Rosenberg GA, Wallin A, Dichgans M, Marler JR, Leblanc GG: National Institute of Neurological Disorders and Stroke-Canadian Stroke Network vascular cognitive impairment harmonization standards. Stroke 2006;37:2220-2241.

-5 Petersen RC: Mild cognitive impairment as a diagnostic entity. J Intern Med 2004;256:183-194.

-6 Morris JC, Roe CM, Grant EA, Head D, Storandt M, Goate AM, Fagan AM, Holtzman DM, Mintun MA: Pittsburgh compound B imaging and prediction of progression from cognitive normality to symptomatic Alzheimer disease. Arch Neurol 2009;66:1469-1475.

-7 Erkinjuntti T, Inzitari D, Pantoni L, Wallin A, Scheltens P, Rockwood K, Desmond DW: Limitations of clinical criteria for the diagnosis of vascular dementia in clinical trials. Is a focus on subcortical vascular dementia a solution? Ann NY Acad Sci 2000;903:262-272.

8 Tomlinson B, Corsellis J: Ageing and the dementias; in Hume Adams J, Corsellis JAN, Duchen LW (eds): Greenfield's Neuropathology. London, Arnold, 1984.

-9 Schneider JA, Arvanitakis Z, Bang W, Bennett DA: Mixed brain pathologies account for most dementia cases in community-dwelling older persons. Neurology 2007;69:2197-2204.

-10 Nordlund A, Rolstad S, Hellström P, Sjögren M, Hansen S, Wallin A: The Göteborg MCI study: mild cognitive impairment is a heterogeneous condition. J Neurol Neurosurg Psychiatry 2005;76:14851490.

-11 Winblad B, Palmer K, Kivipelto M, Jelic V, Fratiglioni L, Wahlund LO, Nordberg A, Backman L, Albert M, Almkvist O, Arai H, Basun H, Blennow K, de Leon M, DeCarli C, Erkinjuntti T, Giacobini E, Graff C, Hardy J, Jack C, Jorm A, Ritchie K, van Duijn C, Visser P, Petersen RC: Mild cognitive impairment - beyond controversies, towards a consensus: report of the International Working Group on Mild Cognitive Impairment. J Intern Med 2004;256:240-246.

12 American Psychiatric Association: Diagnostic and Statistical Manual of Mental Disorders, ed 3, revised, Washington, American Psychiatric Association, 1987.

-13 McKhann G, Drachman D, Folstein M, Katzman R, Price D, Stadlan EM: Clinical diagnosis of Alzheimer's disease: report of the NINCDS-ADRDA Work Group under the auspices of Department of Health and Human Services Task Force on Alzheimer's Disease. Neurology 1984;34:939-944.

14 World Health Organization: The ICD-10 Classification of Mental and Behavioural Disorders. Geneva, World Health Organization, 1992.

-15 Erkinjuntti T, Inzitari D, Pantoni L, Wallin A, Scheltens P, Rockwood K, Roman GC, Chui H, Desmond DW: Research criteria for subcortical vascular dementia in clinical trials. J Neural Transm Suppl 2000;59:23-30.

-16 Hindley NJ, Jobst KA, King E, Barnetson L, Smith A, Haigh AM: High acceptability and low morbidity of diagnostic lumbar puncture in elderly subjects of mixed cognitive status. Acta Neurol Scand 1995;91:405-411.

-17 Clarke R, Smith AD, Jobst KA, Refsum H, Sutton L, Ueland PM: Folate, vitamin B12, and serum total homocysteine levels in confirmed Alzheimer disease. Arch Neurol 1998;55:1449-1455.

18 Roth M, Huppert FA, Tym E, Mountjoy CQ: CAMDEX: The Cambridge Examination for Mental Disorders of the Elderly. Cambridge, Cambridge University Press, 1988

19 Benjamini Y, Hochberg Y: Controlling the false discovery rate: a practical and powerful approach to multiple testing. J R Stat Soc Ser B 1995;57:289-300.

20 Bylesjö M, Rantalainen M, Cloarec O, Nicholson J, Holmes E, Trygg J: OPLS discriminant analysis: combining the strengths of PLS-DA and SIMCA classification. J Chemometrics 2007;20:341-351.

-21 Trygg J, Wold S: Orthogonal projections to latent structures (O-PLS). J Chemometrics 2002;16:119128. 
-22 Eastment H, Krzanowski W: Crossvalidatory choice of the number of components from a principal component analysis. Technometrics 1982;24:73-77.

23 Youden WJ: Index for rating diagnostic tests. Cancer 1950;3:32-35.

24 Kalsheker N: Alpha 1-antitrypsin: structure, function and molecular biology of the gene. Biosci Rep 1989;9:129-138.

-25 Gardner J, Ghorpade A: Tissue inhibitor of metalloproteinase (TIMP)-1: the TIMPed balance of matrix metalloproteinases in the central nervous system. J Neurosci Res 2003;74:801-806.

-26 Erickson LA, Schleef RR, Ny T, Loskutoff DJ: The fibrinolytic system of the vascular wall. Clin Haematol 1985;14:513-530.

-27 Schousboe I: $\beta_{2}$-Glycoprotein I: a plasma inhibitor of the contact activation of the intrinsic blood coagulation pathway. Blood 1985;66:1086-1091.

-28 Wyss-Coray T, Mucke L: Inflammation in neurodegenerative disease - a double-edged sword. Neuron 2002;35:419-432.

-29 Bots ML, Breteler MM, van Kooten F, Haverkate F, Meijer P, Koudstaal PJ, Grobbee DE, Kluft C: Coagulation and fibrinolysis markers and risk of dementia. The Dutch Vascular Factors in Dementia Study. Haemostasis 1998;28:216-222.

- 30 Steinacker P, Mollenhauer B, Bibl M, Cepek L, Esselmann H, Brechlin P, Lewczuk P, Poser S, Kretzschmar HA, Wiltfang J, Trenkwalder C, Otto M: Heart fatty acid binding protein as a potential diagnostic marker for neurodegenerative diseases. Neurosci Lett 2004;370:36-39.

- 31 Buchhave P, Zetterberg H, Blennow K, Minthon L, Janciauskiene S, Hansson O: Soluble TNF receptors are associated with $A \beta$ metabolism and conversion to dementia in subjects with mild cognitive impairment. Neurobiol Aging 2010;31:1877-1884.

-32 Ganguli M, Burmeister LA, Seaberg EC, Belle S, DeKosky ST: Association between dementia and elevated TSH: a community-based study. Biol Psychiatry 1996;40:714-725.

- 33 Blennow K, Wallin A, Uhlemann C, Gottfries CG: White-matter lesions on CT in Alzheimer patients: relation to clinical symptomatology and vascular factors. Acta Neurol Scand 1991;83:187-193.

- 34 Mattsson N, Zetterberg H, Hansson O, Andreasen N, Parnetti L, Jonsson M, Herukka SK, van der Flier WM, Blankenstein MA, Ewers M, Rich K, Kaiser E, Verbeek M, Tsolaki M, Mulugeta E, Rosen E, Aarsland D, Visser PJ, Schroder J, Marcusson J, de Leon M, Hampel H, Scheltens P, Pirttila T, Wallin A, Jonhagen ME, Minthon L, Winblad B, Blennow K: CSF biomarkers and incipient Alzheimer disease in patients with mild cognitive impairment. JAMA 2009;302:385-393. 